\title{
Role of Metallography in a Failure Investigation
}

\author{
D.A. Turnquist*, M.E. Stevenson** \\ * ESI, 4775 Centennial Blvd., Suite 106, Colorado Springs, CO 80919 \\ ** ESI, 6230 Regency Parkway, Norcross, GA 30071
}

When performing failure investigations, the initial appearance of bulk, physical evidence can dictate the ensuing steps undertaken in laboratory analysis. In this case study, macroscopic and microscopic examinations of two wheel bolts, shown in Figure 1, clearly indicated that the mode of failure was fatigue. Often, a significant amount of time is spent looking at the fracture surfaces under a stereomicroscope or in a scanning electron microscope in an attempt to determine the cause, while many more fundamental techniques are ignored. In this investigation, metallography played a key role in determining the root cause of failure.

After determining that the mode of fracture was fatigue, determination of the source of cyclic loading for the fasteners became the primary focus of the investigation. During examination of the mating fracture surfaces, it was noted that welds were present, fusing the bolt heads to the wheel, Figure 2a. The apparent purpose of the welds was to fix the heads and prevent them from rotating. Based on the physical evidence an investigator could be tempted to state that the welds were the cause of failure without any further analysis. But the question was, is that really the case?

Technical literature supports that maintaining proper joint stiffness and preload is required to minimize the likelihood of fatigue failure.[1,2] While welding the heads of the bolts could have an embrittling effect, it does not necessarily explain how fatigue cracks could initiate.

The bolts were sectioned and metallography was performed. Due to the amount of insight that can be gained, metallography should be carefully considered as a tool in most metallurgical failure investigations.[3] Examination of the cross-sections showed that the welds were of poor quality and multiple fractures existed, some of which were outside the heat-affected zone (HAZ), Figure $2 \mathrm{~b}$. Examination of a section taken from a bolt/nut combination showed that cracks were present in the bolt at a significant distance from the HAZ. The position of the crack on the loaded side of the bolt thread would be consistent with the fastener being over-torqued, not the weld.

While the failure mode was fatigue, metallography showed that the root cause of failure was overtorqueing of the fastener, resulting in crack formation of cracks, leading to the loss of joint pre-load, resulting in cyclic loads being applied to the bolt, leading to fatigue fractures; the welds on the bolt heads played no role in the cause of failure

\section{References}

[1] R.W. Hertzberg, Deformation and Fracture Mechanics of Engineering Materials, $4^{\text {th }}$ Edition, Wiley \& Sons, New Jersey, 1996

[2] R.G. Budynas and J.K. Nisbett, Shigley's Mechanical Engineering Design, $8^{\text {th }}$ Edition, McGraw Hill, New York, 2008

[3] D.P. Dennies, How to Organize and Run a Failure Investigation, ASM International, Ohio, 2005 
a)

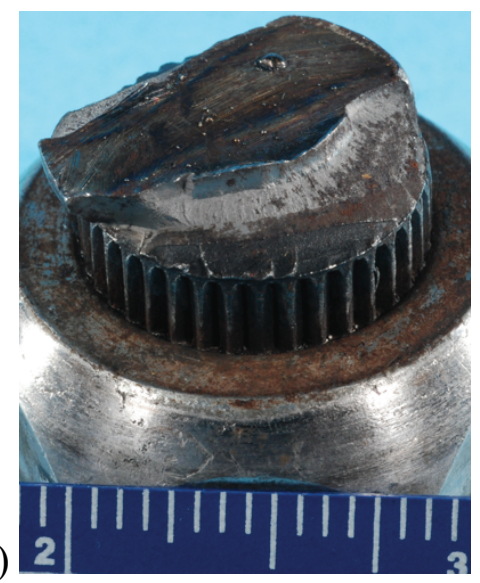

b)

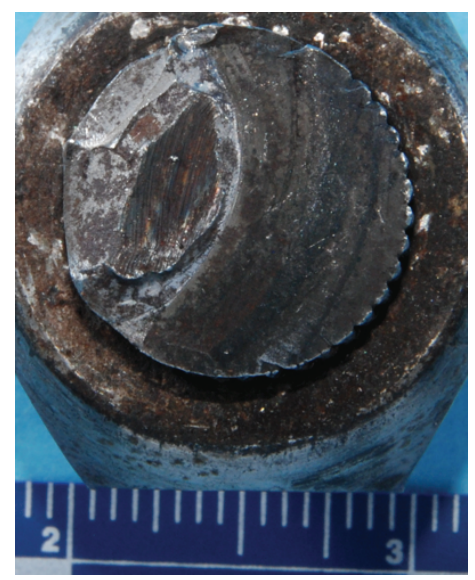

FIG. 1. Photographs showing the heads of two fractured wheel bolts. Beach marks and other indications of fatigue are present on each fracture surface.

a)

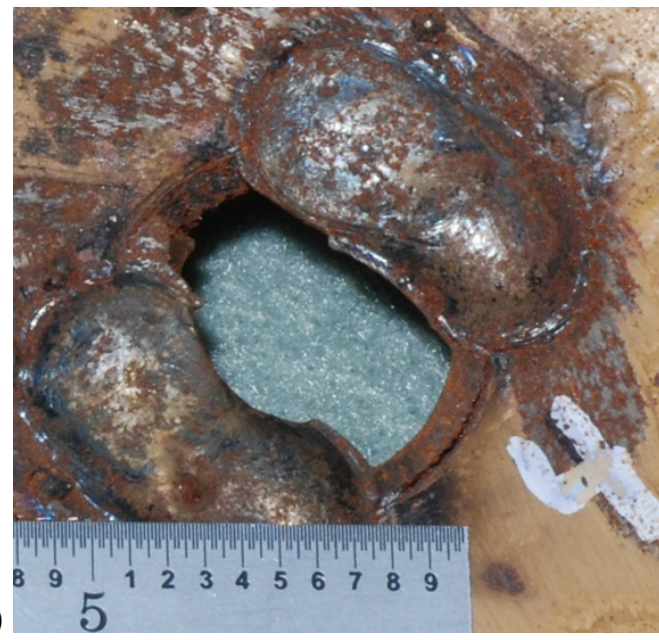

FIG. 2: a) representative photograph showing a weld that was made over the head of one fractured wheel bolt. Welds were placed over three of the bolt heads; b) A macroscopic view of a wheel bolt and weld cross-section shows a poor weld and multiple fractures.

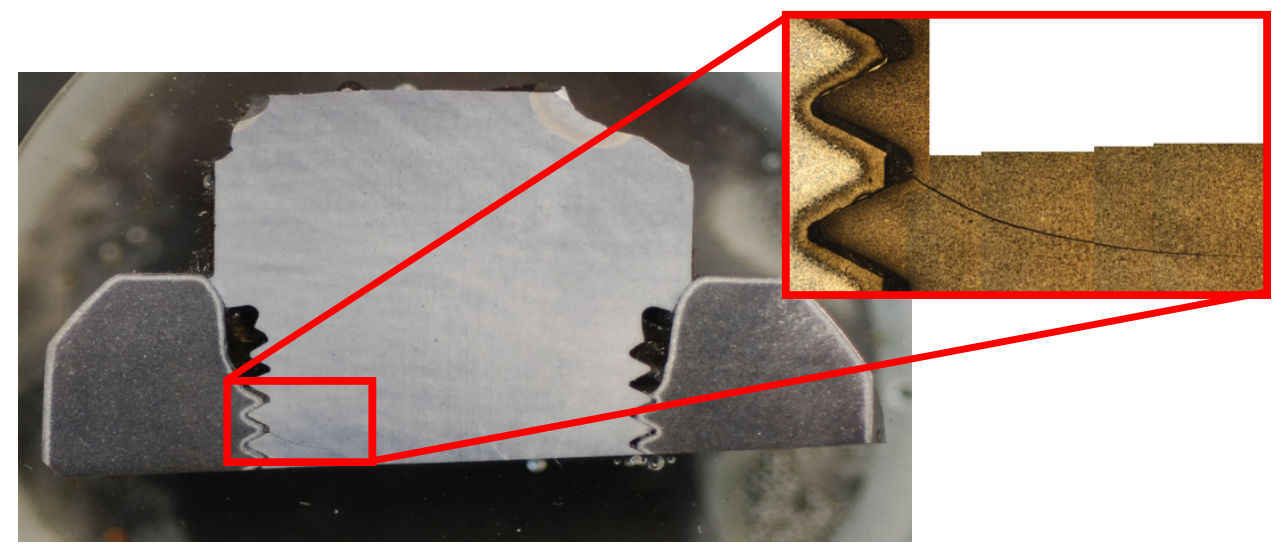

FIG 3. Metallography revealed another crack located at the second thread of engagement. 